\title{
MICROSURGICAL ANATOMY OF THE ARTERIAL COMPARTMENT OF THE CAVERNOUS SINUS
}

\author{
Analysis of 24 cavernous sinus
}

\author{
Gustavo Isolan', Evandro de Oliveira², João Paulo Mattos'
}

\begin{abstract}
The cavernous sinus is a complex compartment situated in both sides of the sella turcica, being its microsurgical anatomy knowledge of fundamental importance when consider to approach surgically. We studied the arterial microanatomy of 24 cavernous sinus at the microsurgical laboratory, considering that in all the internal carotid artery were filled with colored latex. The meningohypophyseal trunk was present in 18 cases $(75 \%)$ with its origin in intracavernous portion of the internal carotid artery. In relation to the 18 presented cases with meningohypophyseal trunk, $14(77.7 \%)$ had a trifurcate and $4(23.3 \%)$ had a bifurcate pattern. The tentorial artery was present in all. Its origin was observed, arising from the meningohypophyseal trunk in $17(70.8 \%)$ and as an isolated artery in some extension of the intracavernous portion in 7 (29.1\%). An accessory tentorial artery was found in one specimen. The dorsal meningeal artery was present in 22 cases $(91.6 \%)$. Its origin was in the meningohypophyseal trunk in 17 cases $(77.2 \%)$, arising from internal carotid artery in 4 cases $(18.1 \%)$ and from inferior hypophyseal artery in one case $(4.1 \%)$. The inferior hypophyseal artery was present in all cases, having its origin at the meningohypophyseal trunk in 16 cases $(66.6 \%)$. In the remaining 8 cases $(33.3 \%)$ the artery was found arising alone from the intracavernous portion also. The artery of the inferior cavernous sinus or inferolateral trunk was present in all cases and had its origin from internal carotid artery in its intracavernous segment. The McConnell's artery was not found in any cavernous sinus.
\end{abstract}

KEY WORDS: cavernous sinus, microsurgical anatomy, internal carotid artery.

\section{Microanatomia do compartimento arterial do seio cavernoso e suas variações: análise de 24 seios cavernosos}

RESUMO - O seio cavernoso é estrutura complexa localizada de cada lado da sela túrcica, sendo seu conhecimento microanatômico indispensável quando se considera abordar cirurgicamente esta região. Estudaramos em laboratório de microcirurgia a microanatomia dos componentes arteriais deste espaço em 24 seios cavernosos, sendo que em todos a artéria carótida interna estava preenchida com látex colorido. $O$ tronco meningo-hipofisário esteve presente em 18 casos (75\%). Quando ausente, as artérias constituintes deste tronco se originaram diretamente das artérias carótidas internas (ACls) intracavernosas. Quando presente, em 14 casos (77,7\%), estavam trifurcados e em 4 casos $(23,3 \%)$ bifurcados. A artéria tentorial foi identificada em todos os casos, porém sua origem foi variada, ocorrendo no tronco meningohipofisário em 17 casos (70,8\%) e na artéria carótida interna intracavernosa em 7 casos $(29,1 \%)$. Em 1 caso verificou-se a presença de uma artéria tentorial acessória. A artéria meningéia dorsal estava presente em 22 casos $(91,6 \%)$ e ausente em 2 casos $(8,4 \%)$. Nos seios cavernosos onde a mesma foi identificada, a sua origem ocorreu no tronco meningo-hipofisário em 17 casos (77,2\%), da ACl intracavernosa em 4 casos (18,1\%) e da artéria hipofisária inferior em 1 caso $(4,1 \%)$. A artéria hipofisária inferior foi identificada em todos os casos, tendo sua origem no tronco meningo-hipofisário em $16(66,6 \%)$ e na $\mathrm{ACl}$ intracavernosa em 8 $(33,3 \%)$ casos. A artéria inferior do seio cavernoso ou tronco ínfero-lateral foi isolada em $100 \%$ dos casos e em todos se originou da $\mathrm{ACl}$ intracavernosa. A artéria de McConnell não foi identificada em nenhum seio cavernoso.

PALAVRAS-CHAVE: seio cavernoso, microanatomia cirúrgica, artéria carótida interna.

\footnotetext{
${ }^{1}$ Neurosurgeon, Fellowship Research .Laboratório de Microcirurgia, Hospital Beneficência Portuguesa de São Paulo. Instituto de Ciências Neurológicas, São Paulo SP, Brazil; ${ }^{2}$ Neurosurgeon, Director of Instituto de Ciências Neurológicas, Professor of the Departament de Neurosurgery Universidade Estadual de Campinas (UNICAMP) Campinas SP, Brazil.
}

Received 4 June 2004, received in final form 15 October 2004. Accepted 30 November 2004.

Dr. Evandro de Oliveira - Instituto de Ciências Neurológicas - Praça Amadeu Amaral 27/5 andar - 01327-010 São Paulo SP - Brasil. E-mail: icne@uol.com.br 
The cavernous sinus is a complex region localized around the sella turcica where a significant number of neural and vascular structures are in close relation in apparent disarray. For this reason, the study of the anatomy of the cavernous sinus region is observed since 1695 . It has been also defined as a compartment covered by dura where the cavernous portion of the internal carotid artery is inserted ${ }^{1-7}$.

Initial cavernous sinus poor surgical results have led to conservative attitude towards those lesions leading the neurosurgeons to avoid the surgical access to this region. With the development of microsurgical techniques, advances in neuroimaging, neuroanesthesia, post-operative intensive care, and the knowledge of the microsurgical anatomy of the region, the surgical treatment became possible with minimal morbidity.

An expressive number of tumoral, inflamatory and vascular lesions can arise from or spread to the region of the cavernous sinus. The vascular anatomical knowledge and its variations are of vital importance considering the difficult access to this region and the management of this kind of pathologies.

\section{METHOD}

Twenty-four fixed cavernous sinus specimens were prepared with red colored latex injection in the arterial tree for dissection and identification of the internal carotid artery (ICA) and its branches under microscopic magnification. The study was realized at Microanatomy Laboratory in Beneficência Portuguesa Hospital, São Paulo, Brazil. The skull base pieces were extracted in a compact block in order to preserve the skull base vessels for further latex injection.

The limits of the specimens was: anterior, the middle plane of the orbits; lateral, the lateral region to foramina spinosum and posterior, a line posterior to the region of the clivus. The specimens were dissected under variable magnification using a D.F. Vasconcellos M900 model microscopy, a high speed Midas Rex III drill model and microsurgical instruments as microscissors, Metzembaum scissors, Rothon microdissectors, a House-Urban fixation system to keep the specimen fixed and an adequate suction and irrigation system to avoid damage to the anatomical structures.

A routine dissection was made following the steps as used in the courses of cavernous sinus anatomy offered by this same institution annually. These steps are as follows: (1) fixation of the skull base block in the HouseUrban device; (2) squared shape dura incision from the middle portion of the lesser sphenoid wing to the planum sphenoidale for bone exposure of the anterior clinoid process, optic canal, planum sphenoidale and sphenoid edge; (3) middle fossa peeling leaving the reticular membrane adherent to the nerves in the lateral wall of the cavernous sinus, (4) a high speed drill is used to achieve a bone removal from the posterior orbital roof and the anterior clinoid process exposing the anteromedial triangle with identification of the distal and proximal ICA dural rings preserving the integrity of the carotidoculomotor membrane; (5) falciform ligament incision followed by lifting of the optic nerve permitting the incision of the distal dural ring under the optic nerve and between ICA and the ophthalmic artery allows the clinoid portion of the ICA to be exposed and mobilized; (5) dural incision in the oculomotor triangle immediately medial and parallel to the oculomotor nerve to the superior orbital fissure with carefully separation of the cranial nerves from the reticular membrane exposing the VIth nerve, the horizontal segment of the ICA, the inferior cavernous sinus artery, the meningohipophyseal trunk and its branches; (6) opening of the Parkinson's triangle with identification of the vertical ICA segment, proximal curvature, meningohipophyseal trunk and its branches; and (7) identification of the cavernous sinus inferior artery in the anterolateral triangle.

The branches of the cavernous segment of the ICA were studied in respect to the frequency of appearance, its origin and anastomotic patterns in all 24 cavernous sinus. The tentorial artery, dorsal meningeal artery, superior hipophyseal artery, their relations to the meningohipophyseal trunk and the inferior artery of the cavernous sinus and the McConnell's artery were all studied. The origin and relation between the ophthalmic artery and ICA was evaluated also.

\section{RESULTS}

The ophthalmic artery was found in every case and its origin was located at the intradural ICA in all.

The meningohipophyseal trunk was present in 18 cases $(75 \%)$ (Fig 1). A trifurcation was found in 14 cases $(77.7 \%)$ and a bifurcation in $4(23.3 \%)$. The origin of its branches occurred directly from the cavernous segment of the ICA in the remaining six cases (Fig 2).

The tentorial artery was found in all cases. Seven cases $(29.1 \%)$ were found arising directly from intracavernous ICA and 17 cases (70.9\%) from meningohipophyseal trunk. An accessory tentorial artery was present in one cavernous sinus.

The dorsal meningeal artery (Fig 3) was observed in 22 specimens (91.6\%). In our study, this artery is the most variable vessel concerning its origin as in $17(77.2 \%)$ cases was found to be a branch of the meningohipophyseal trunk, in $4(18.1 \%)$ from ICA and the last one was a division of the inferior hipophyseal artery.

The inferior hipophyseal artery was present in all. Its origin from meningohipophyseal trunk was fo- 


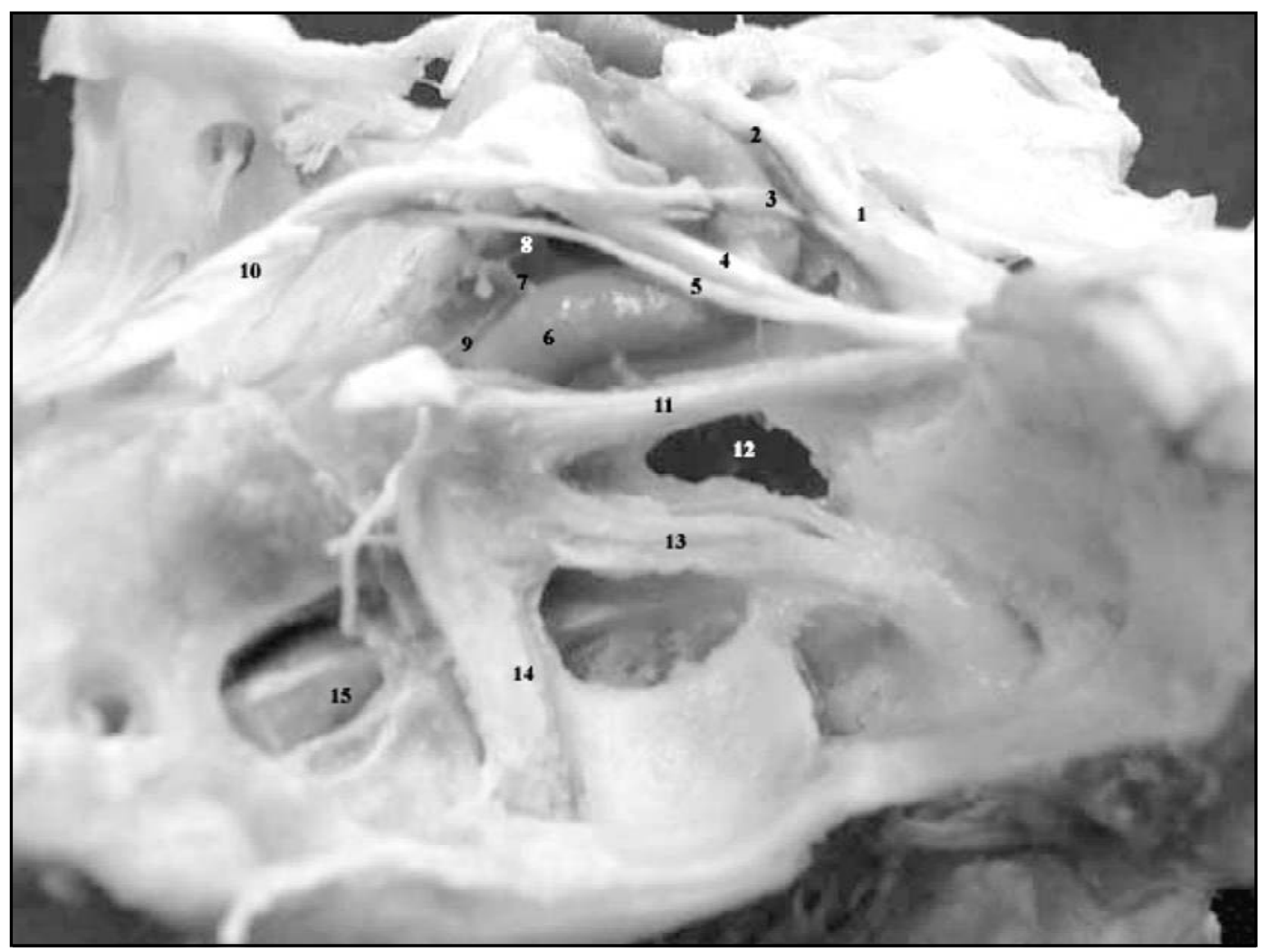

Fig 1. A lateral view of the cavernous sinus. The trifurcated meningohipophyseal trunk is well visualized at the dorsal aspect of the posterior curvature. The tentorial artery is directed posterolaterally going to the tentorial face. The dorsal meningeal artery has a posteroinferior and medial direction to go through the posterosuperior venous space. The inferior hipophyseal artery goes to the lateral part of the posterior lobe of the pituitary gland in an anteromedial way. The inferior artery of the cavernous sinus has its origin at the lateral wall of the ICA and is directed inferiorlly. The ophthalmic artery has its origin in the intradural compartment as usually seen. 1.optic nerve, 2. ophthalmic artery, 3. distal dural ring, 4. clinoid segment of the ICA, 5. IVth nerve, 6.cavernous portion of the ICA, 7. meningohipophyseal trunk, 8. inferior hipophy seal artery, 9. dorsal meningeal artery, 10. tentorial artery, 11. ophthalmic division of the trigeminal nerve (V1) , 12. sphenoid sinus, 13. V2, 14. V3, 15. petrous segment of the ICA.

und in 16 cases (66.6\%) and the last 8 arteries (33.3\%) arising from the ICA. The inferior artery of the cavernous sinus also known as inferolateral trunk was present in $100 \%$ arising from the ICA in all.

McConnell's artery was not found in this series.

The anastomosis among the different branches was present in two cavernous sinus. The shunt between inferior artery of the cavernous sinus and meningohipophyseal trunk in one and the inferior artery of the cavernous sinus and tentorial artery in the other was noticed.

\section{DISCUSSION}

The cavernous portion of the ICA has usually three main branches: the meningohipophyseal trunk, the inferior artery of the cavernous sinus and the McConnell's artery. The major branch is often the meningohipophyseal trunk as it is the most constant artery that usually gives rise to three branches. Its origin is described medially in the middle third of the medial curvature of the ICA. Its three branches: tentorial artery, dorsal meningeal artery and the inferior hipophyseal artery. The inferior artery of the cavernous sinus arises inferolaterally or lateral to the horizontal portion of the cavernous ICA. The McConnell' artery has its origin in the medial aspect of the distal part of the horizontal segment of the cavernous ICA and supplies the pituitary capsule. It is found in $20 \%$ to $28 \%$ of the cases ${ }^{2,3}$.

The ophthalmic artery is usually found immediately distal to the distal dural ring; however, it is also described arising at the intracavernous portion, clinoid segment and even from the middle meningeal artery ${ }^{1}$. 


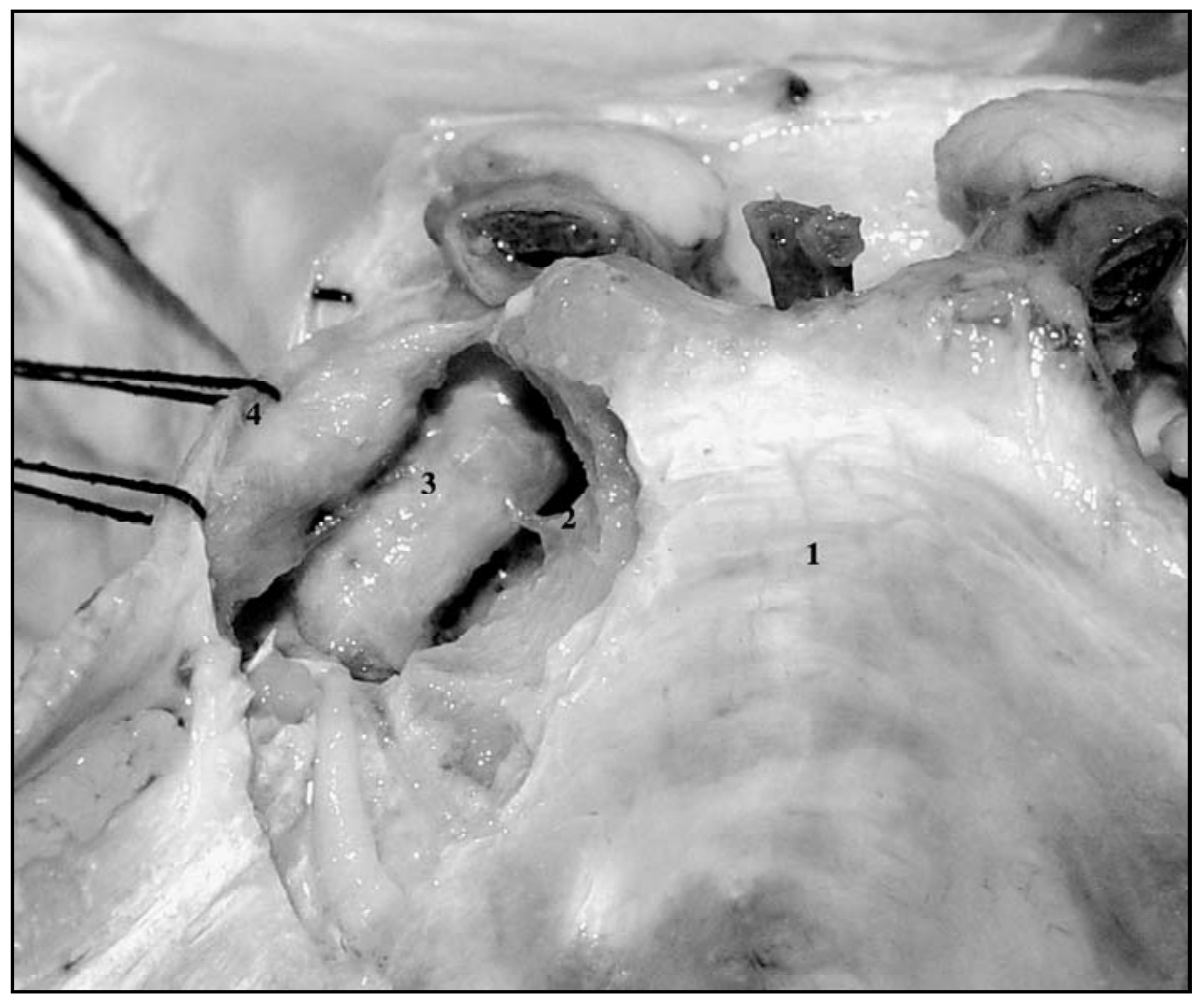

Fig 2. A left posterior view of the resected posterior wall of the cavernous sinus. The poste rior aspect of the dorsal part of the ICA posterior vertical segment is seen without meningo hipophyseal trunk. 1. clivus, 2. dorsal meningeal artery, 3. tentorial artery, 4. tentorial edge.

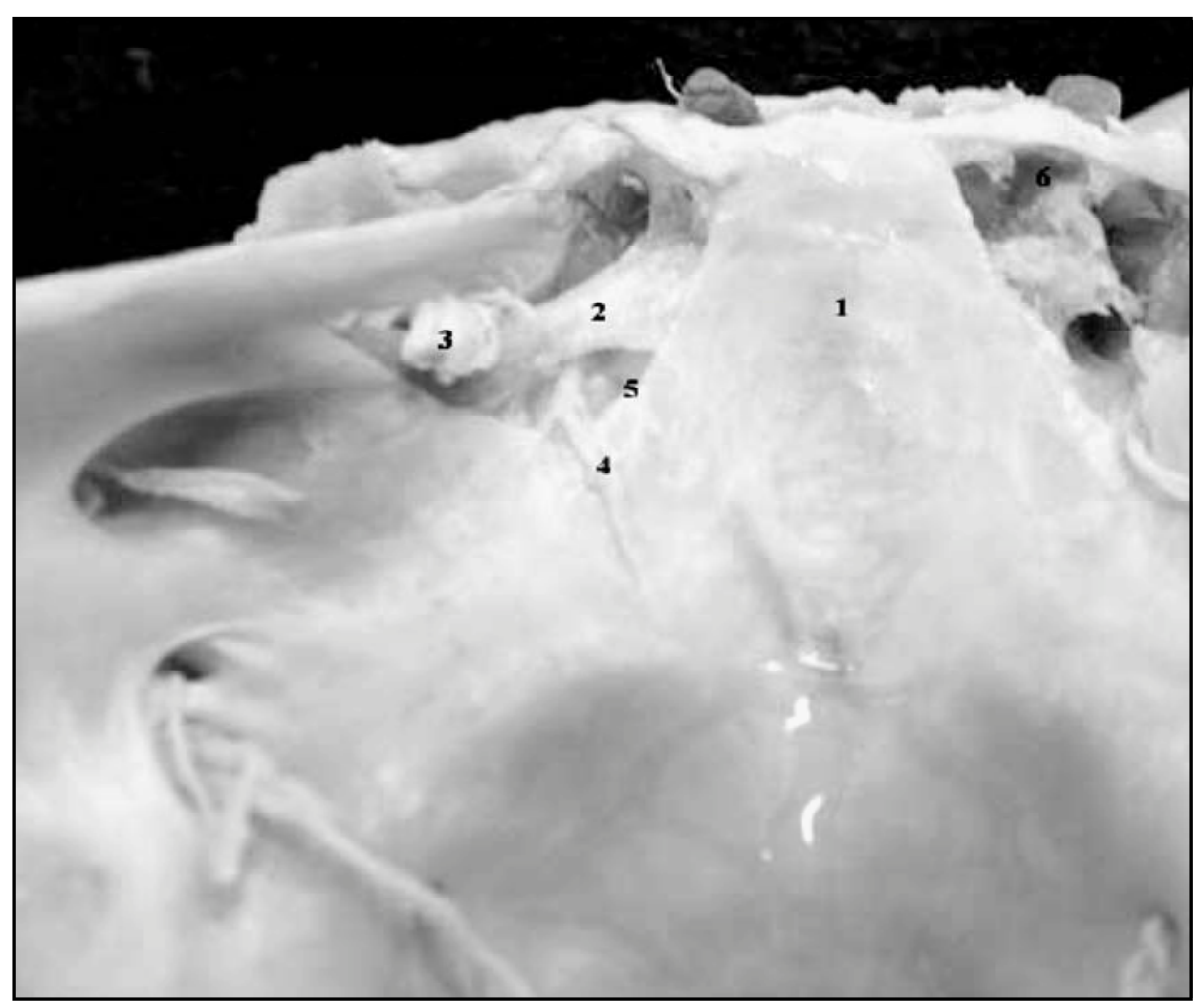

Fig 3. A posterior view of the clivus region and the left cavernous sinus. 1. clivus, 2. Gruber's ligament, 3. trigeminal nerve, 4. abduscent nerve, 5. dorsal meningeal artery. 
Accordingly to Rhoton ${ }^{8}$, there is a five staged division of the intracavernous segment of the ICA: (1) vertical posterior; (2) posterior curvature; (3) horizontal segment; (4) anterior curvature and (5) anterior vertical segment.

The posterior vertical segment is its ascendent portion beginning where it enters the cavernous sinus at the level of the foramen lacerum and finishes when it curves anteriorly. The posterior curvature is located between the ascendent and horizontal segment laterally to the posterior clinoid. The horizontal portion is directed slightly lateral and finishes when the vessel curves approximately 90 degrees anteriorly, the anterior curvature, in the inferior and medial aspect of the anterior clinoid process, so the ICA assumes a vertical direction going to perforate the roof of the cavernous sinus to achieve the subaracnoid space, the anterior vertical segment.

The meningohipophyseal trunk is present is $90 \%$ to $100 \%$ of the cavernous sinus ${ }^{3,4,9,10}$. The tentorial edge, the dura covering the basilar plexus and the posterior part of the pituitary gland are all supplied by the branches of the meningohipophyseal trunk, which are trifurcated in $70 \%$ of the cases $^{2}$. It can also be hypoplastic or absent and its branches can arise directly form the cavernous portion of ICA ${ }^{1,9}$.

The tentorial artery is found in $100 \%$ of the cases $^{1,11}$. It is also called Bernasconi-Cassinari, accordingly to his angiographically description of a welldeveloped tentorial artery in tentorial meningiomas. The tentorial artery can also arise from the ICA and from the inferior artery of the cavernous sinus ${ }^{5,12}$. An accessory tentorial artery can be found if a hypoplastic tentorial artery is present. The former can be originated from the inferior artery of the cavernous sinus or from the middle meningeal artery. The tentorial artery supplies some extension of the trochlear and oculomotor nerves as can send branches to the roof of the cavernous sinus with rich anastomotic pattern with meningeal branches from ophthalmic artery.

The dorsal meningeal artery supplies the dura of the clivus and posterior wall of the cavernous sinus. It arises usually from the meningohipophyseal trunk in $82 \%$ to $90 \%{ }^{1,2}$. In the remaining cases, it can arise from the cavernous segment of the ICA, the inferior hipophyseal artery or from inferior artery of the cavernous sinus ${ }^{1,2}$. It can be absent in $10 \%$ of the cases ${ }^{12}$. The dorsal meningeal artery is directed inferoposteriorlly and medially crossing the cavernous venous space in its superoposterior portion going through the space under the petrosphenoid ligament also known as Gruber's ligament. The dorsal meningeal artery is situated medial to the abduscent nerve before its entrance in the basilar plexus ending at the dura covering the basilar bone. At this point, this artery will find its contralateral mate forming an arterial anastomotic network. The abduscent nerve is supplied by branches from the dorsal meningeal artery at the level of the Dorello's canal. In an extensive series of 50 cases $^{11}$, the dorsal meningeal artery was found in every case. The location was variable but the most common pattern was a large medial artery in $52 \%$ of those meningohipophyseal trunks. A divided branch was also found in $38 \%$ and a small lateral branch was identified in $10 \%$.

The inferior hipophyseal artery arises from the meningohipophyseal trunk in $70 \%$ to $80 \%^{1,2}$. It can be found at the medial aspect of the cavernous portion of the ICA also. After that, the artery will course anterior and medial crossing the medial venous space to become close to the posterior wall in the floor of the pituitary gland. At this point, the artery usually will be divided in two or three subdivisions called superior and inferior branches going superior and inferior respectively, ending at the hipophyseal sulcus that separates the anterior and posterior pituitary lobes. Those branches meet the same arteries of the contralateral side forming an anastomic plexus. In a series of 30 cases, the inferior hipophyseal branch had its origin at the tentorial artery in $10 \%$ and in 1 specimen the McConnell's artery gives rise to this artery ${ }^{12}$. Reisch et al. ${ }^{11}$, found the inferior hipophyseal artery in $82 \%$ of cases after the study of 50 cavernous sinus.

The inferior artery of the cavernous sinus is also known as inferolateral trunk. This artery was found by Parkinson in $80 \%$ of the cases in his large series of 200 cavernous sinus studied ${ }^{13}$. It has its origin at the lateral portion of the middle third of the horizontal segment of the ICA, approximately 5 to $8 \mathrm{~mm}$ distal to the meningohipophyseal trunk ${ }^{1}$. It arises directly from the ICA in $84 \%$ and from meningohipophyseal trunk in $6 \%{ }^{1}$. This artery supplies the region around the foramen spinosum making an anastomotic network with the middle meningeal and accessory middle meningeal branches. Of most importance is the fact that it is the main feeder of the gasserian ganglion ${ }^{2}$. 
The McConnell's artery also called capsular artery is the lesser common branch found at the intracavernous ICA. It was identified in just $25 \%$ to $30 \%$ of the cases ${ }^{1-3,12}$ in spite of previous report made by McConnell who described in $50 \%$ of those cases ${ }^{2}$.

\section{REFERENCES}

1. Rhoton AR Jr. The cavernous sinus, the cavernous venous plexus, and the carotid collar. Neurosurgery 2002;51(Suppl 1):375-410.

2. Siang CC. Microanatomia do seio cavernoso. Tese, Escola Paulista de Medicina. São Paulo, 1992.

3. Harris FS, Rhoton, AL jr. Anatomy of the cavernous sinus: a microsurgical study. J Neurosurg 1976;45:169-80.

4. Renn WH, Rhoton AL Jr. Microsurgical anatomy of the sellar region. J Neurosurg 1975;43:288-298.

5. Meneses MS, Molinari D, Forte M, et al. Surgical considerations about the anterior syphon knee of the internal carotid artery: an anatomical study. Arq Neuropsiquiatr 1995;53:34-37.
6. Seoane E, Rhoton AL Jr, Oliveira E. Microsurgical anatomy of the dural collar (carotid collar) and rings around the clinoid segment of the internal carotid artery. Neurosurgery 1998;42:869-884.

7. Sousa DRJ, Muniz JAPC, Tamega OJ. Morphology of the walls of the cavernous sinus of Cebus apella (tufted capuchin monkey). A rq Neuropsiquiatr 1999;57:735-739.

8. Rhoton A.L Jr, Inoue T. Microsu rgical approach to the cavernous sinus. In: Clinical neurosurgery. Baltimore: Willian \& Wilkins, 1989.391-439.

9. Tran-dinh H. Cavernous branches of the internal carotid artery: anatomy and nomenclature. Neurosurgery 1987;20:205-210.

10. Knosp E, Muller G, Perneczky A. The paraclinoid carotid artery: anatomical aspects of a microsu rgical approach. Neurosurgery 1988;22:896-901.

11. Reisch R, Vutskits L, Patonay L, Fries G The meningohypofiseal trunk and its blood supply to different intracranial structures: an anatomical study. Minim Invasive Neurosurg 1996;39:78-81.

12. Beltz N, Taner D Anatomical variations of the intracavernous branches of the internal carotid artery with reference to the relationship of the internal carotid artery and sixth cranial nerve: a microsurgical study. Acta Anatomica 1990;138:238-245.

13. Parkinson D. A surgical approach to the cavernous portion of the carotid artery: anatomical studies and case report. J Neurosurg 1965;23:474-483. 